\title{
Complete histological resolution of collagenous sprue
}

\author{
Hugh J Freeman $\mathrm{MD}^{1}$, Jennifer E Davis $\mathrm{MB}^{2}$, Danny M Myers $\mathrm{MD}^{3}$
}

HJ Freeman, JE Davis, DM Myers. Complete histological resolution of collagenous sprue. Can J Gastroenterol 2004;18(5):333-336.

A 65-year-old woman developed a watery diarrhea syndrome with collagenous colitis. Later, weight loss and hypoalbuminemia were documented. This prompted small bowel biopsies that showed pathological changes of collagenous sprue. An apparent treatment response to a gluten-free diet and prednisone resulted in reduced diarrhea, weight gain and normalization of serum albumin. Later repeated biopsies from multiple small and large bowel sites over a period of over three years, however, showed reversion to normal small intestinal mucosa but persistent collagenous colitis. These results indicate that collagenous inflammatory disease may be a far more extensive process in the gastrointestinal tract than is currently appreciated. Moreover, collagenous colitis may be a clinical signal that occult small intestinal disease is present. Finally, collagenous sprue may, in some instances, be a completely reversible small intestinal disorder.

Key Words: Celiac disease; Collagenous colitis; Collagenous duodenitis; Collagenous sprue; Inflammatory bowel disease

\section{Une résolution histologique complète de sprue collagène}

Une femme de 65 ans a développé un syndrome de diarrhée aqueuse accompagné de colite collagène. Une perte de poids et une hypoalbuminémie ont ensuite été documentées. Cette observation a suscité des biopsies de l'intestin grêle qui ont révélé des modifications pathologiques de la sprue collagène. Une réaction apparente au traitement par un régime sans gluten et de la prednisone a favorisé la diminution de la diarrhée, un gain de poids et une normalisation de l'albumine sérique. Plus tard, des biopsies répétées de multiples foyers de l'intestin grêle et du gros intestin réparties sur une période de plus de trois ans ont toutefois révélé un retour à une muqueuse normale de l'intestin grêle, mais une colite collagène persistante. D'après ces résultats, la maladie inflammatoire collagène pourrait constituer un processus inflammatoire beaucoup plus généralisé du tube digestif qu'on ne l'a évalué jusqu'à présent. De plus, la colite collagène pourrait être un signe clinique de maladie occulte de l'intestin grêle. Enfin, la sprue collagène pourrait, dans certains cas, être un trouble intestinal entièrement réversible de l'intestin grêle.
In 1970, Weinstein et al (1) described a patient with celiac disease who later became refractory to a gluten-free diet. Detailed small intestinal histologic studies showed 'flattened' villous architecture and distinct subepithelial eosinophilic hyaline deposits having histochemical and ultrastructural features of collagen. As a result, this entity was labelled collagenous sprue. The investigators also noted that a similar small bowel lesion may have been described as early as 1947 (2). After 1970, additional rare cases of collagenous sprue were described (3-9). Collagenous sprue was often associated with a poor outcome. However, response to a gluten-free diet and steroids was recorded (6). As in celiac disease $(10,11)$, rare patients with collagenous sprue were also reported with a complicating and fatal lymphoma $(12,13)$.

In 1976, a 'new' type of inflammatory colonic disease with watery diarrhea was independently described in three patients $(14,15)$. This was labelled collagenous colitis because of similar histochemical and ultrastructural features to collagenous sprue. Later, collagen deposition was detected in the stomach and small bowel of some patients with collagenous colitis (16-22) and recently, a link between collagenous colitis and celiac disease has been established (23).

The present report describes an elderly woman with chronic diarrhea and detection of collagenous disease in the small and large bowel. Her treatment was associated with histological normalization of her small intestinal biopsies, as well as disappearance of detectable small intestinal, but not colonic, collagen.

\section{CASE PRESENTATION}

A 65-year-old woman was referred in August 2000 because of watery diarrhea of up to 10 episodes per day for six weeks. Slight tenderness was present in the left lower quadrant. Fecal bacterial and parasite studies were negative and an assay for Clostridium difficile toxin was negative. In September 2000, colonoscopy showed sigmoid diverticulosis and multiple colonic biopsies showed features of collagenous colitis (Figures 1 and 2). Empirical trials of Imodium (McNeil Consumer Healthcare, Canada), Pepto-Bismol (Procter \& Gamble Pharmaceuticals, Canada), mesalamine and Questran (BristolMyers Squibb, Canada) were not effective and weight loss of

${ }^{1}$ Departments of Medicine (Gastroenterology) and ${ }^{2}$ Pathology, University of British Columbia, Vancouver, British Columbia; ${ }^{3}$ Shuswap Lake General Hospital, Salmon Arm, British Columbia

Correspondence and reprints: Dr Hugh Freeman, Gastroenterology, University of British Columbia Hospital, 2211 Wesbrook Mall, Vancouver,

British Columbia V6T 1W5. Telephone 604-822-7216, fax 604-822-7236, e-mail hugfree@shaw.ca

Received for publication January 20, 2004. Accepted March 19, 2004 


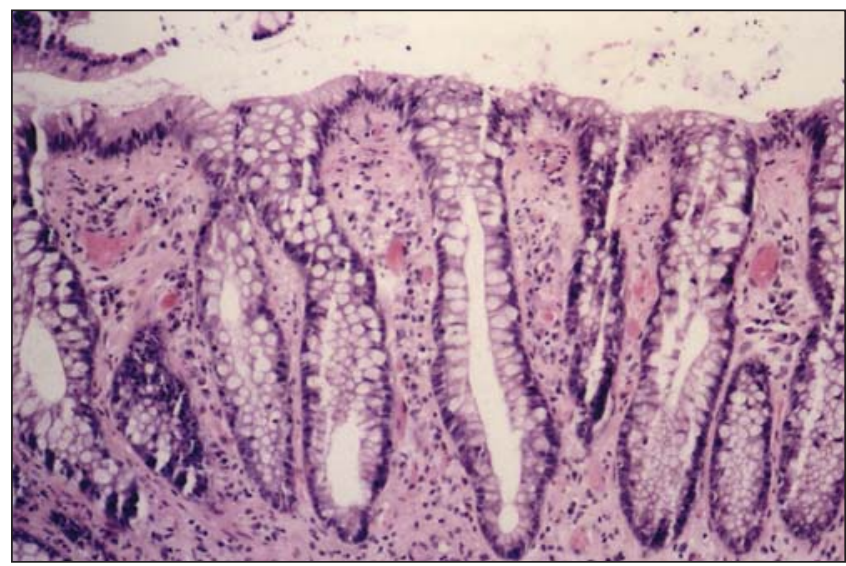

Figure 1) Collagenous colitis with eosinophilic hyaline material in subepithelial region. Increased lymphocytes and plasma cells are present in the lamina propria region, with increased intraepithelial lymphocytes in the surface epithelium (Hematoxylin and eosin stain)

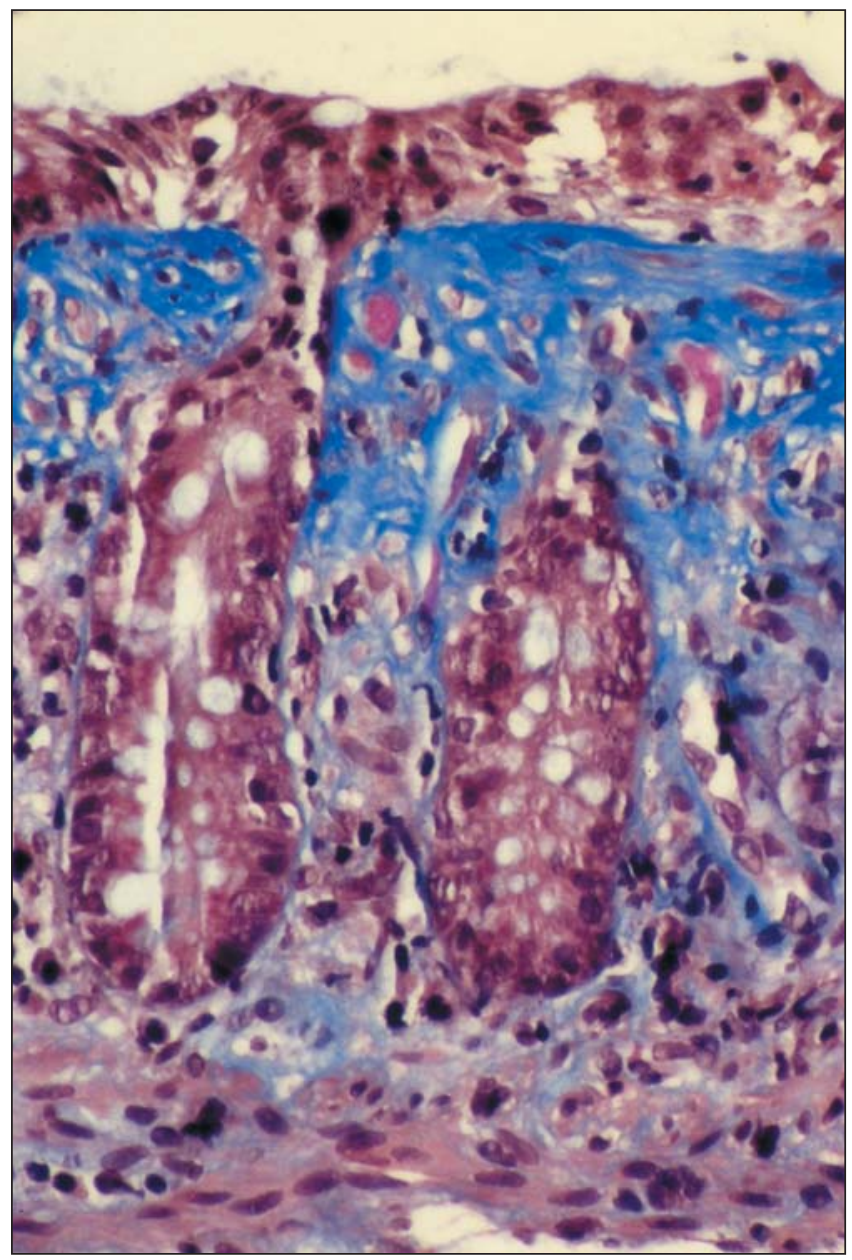

Figure 2) Trichrome-positive staining (blue) in colonic biopsy, particularly in the subepithelial region of the lamina propria (Trichrome stain)

more than $10 \mathrm{~kg}$ was documented. In December 2000, endoscopic biopsies from two separate duodenal sites showed changes of collagenous sprue (Figures 3 to 6). Laboratory blood studies were normal except for a low serum albumin of $31 \mathrm{~g} / \mathrm{L}$. Barium studies of the small bowel were normal. In January 2001,

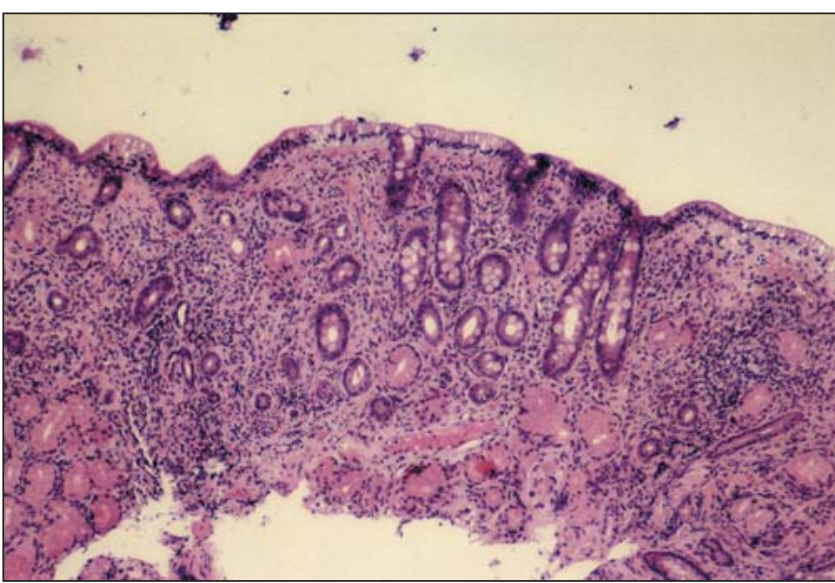

Figure 3) Severely "flattened" small bowel biopsy with eosinophilic hyaline material in the lamina propria, particularly in the subepithelial region (Hematoxylin and eosin stain)

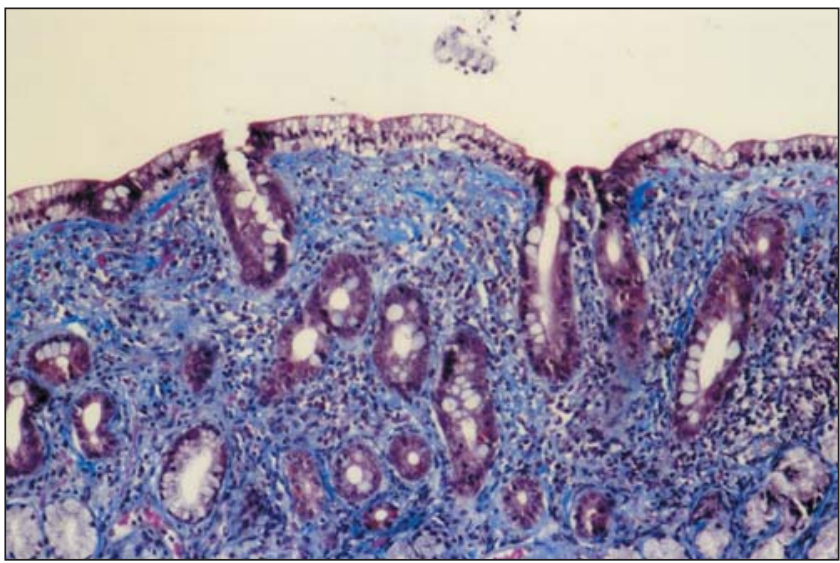

Figure 4) Trichrome-positive small bowel biopsy with prominent blue staining of subepithelial region (Trichrome stain)

treatment with a gluten-free diet led to a partial, but only temporary, improvement in diarrhea frequency to five to seven episodes per day. Because of persistent diarrhea and ongoing weight loss, prednisone $30 \mathrm{mg}$ daily was added. Diarrhea improved to two to four episodes daily, and weight increased by approximately $4 \mathrm{~kg}$ in one month. On two occasions, attempts to taper the prednisone resulted in worsening diarrhea.

In July 2001, multiple colonic biopsies showed persistent collagenous colitis, but multiple small bowel biopsies from four separate duodenal sites were normal (Figure 7). Azathioprine was refused and her symptoms responded to repeated intermittent courses of prednisone. In June 2002, biopsies from multiple colonic sites showed persistent collagenous colitis, but biopsies from two sites in the descending and distal duodenum were normal. She continued on a gluten-free diet alone without prednisone, but her diarrhea persisted, three to four episodes per day.

By September 2002, however, her weight had increased by approximately $15 \mathrm{~kg}$ and her serum albumin was normal at $39 \mathrm{~g} / \mathrm{L}$. Additional duodenal biopsies from two separate sites showed no recurrence of collagenous sprue but multiple 


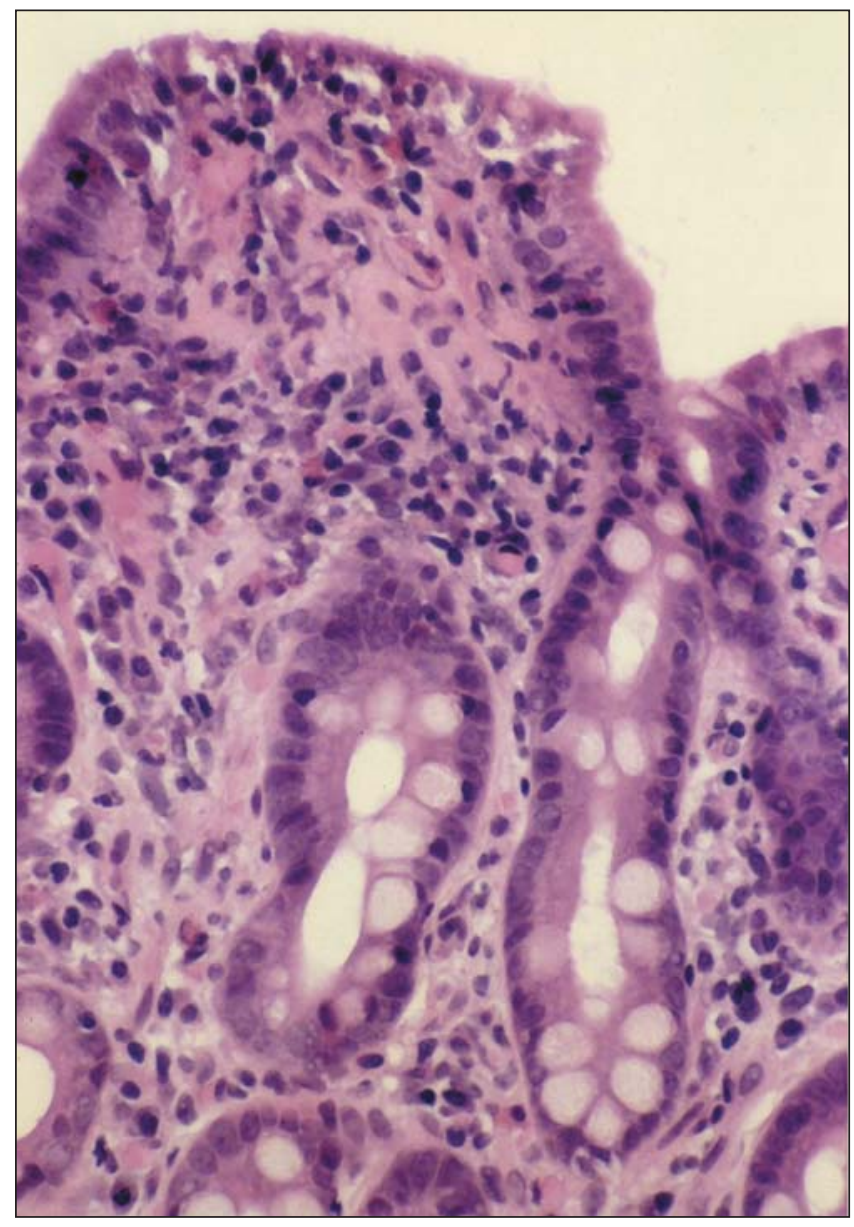

Figure 5) Moderate to severely abnormal small bowel biopsy with eosinophilic hyaline material in the subepithelial region (Hematoxylin and eosin stain)

colonic biopsies showed persistent inflammatory changes. Intermittent watery diarrhea persisted, sometimes up to 10 episodes per day. In August 2003, seven additional biopsies from separate duodenal sites were normal but multiple colonic biopsies showed collagenous colitis. In September 2003, oral budesonide $9 \mathrm{mg}$ daily was associated with further symptomatic improvement, demonstrated by two to four soft or semi-solid stools daily.

\section{DISCUSSION}

Collagenous inflammatory mucosal disease was defined here in both the small and large intestine of a patient with chronic diarrhea. Although this is very unusual, having been recorded in only a handful of cases to date (16-21), these findings confirm that a more extensive pangastrointestinal inflammatory process may occasionally be present. Indeed, the extent of this rather unique type of inflammatory process is probably often underestimated. Detection of collagenous colitis in a patient with chronic diarrhea, for example, would often limit further clinical and endoscopic evaluation, particularly for an upper gastrointestinal tract cause. Indeed, prior studies have documented collagenous gastritis in a patient presenting with collagenous colitis (22). And, in a recent report (23), over 20\% of collagenous colitis patients had another clinically important and closely related clinical disorder, celiac disease. In this latter group of patients, symptomatic improvement

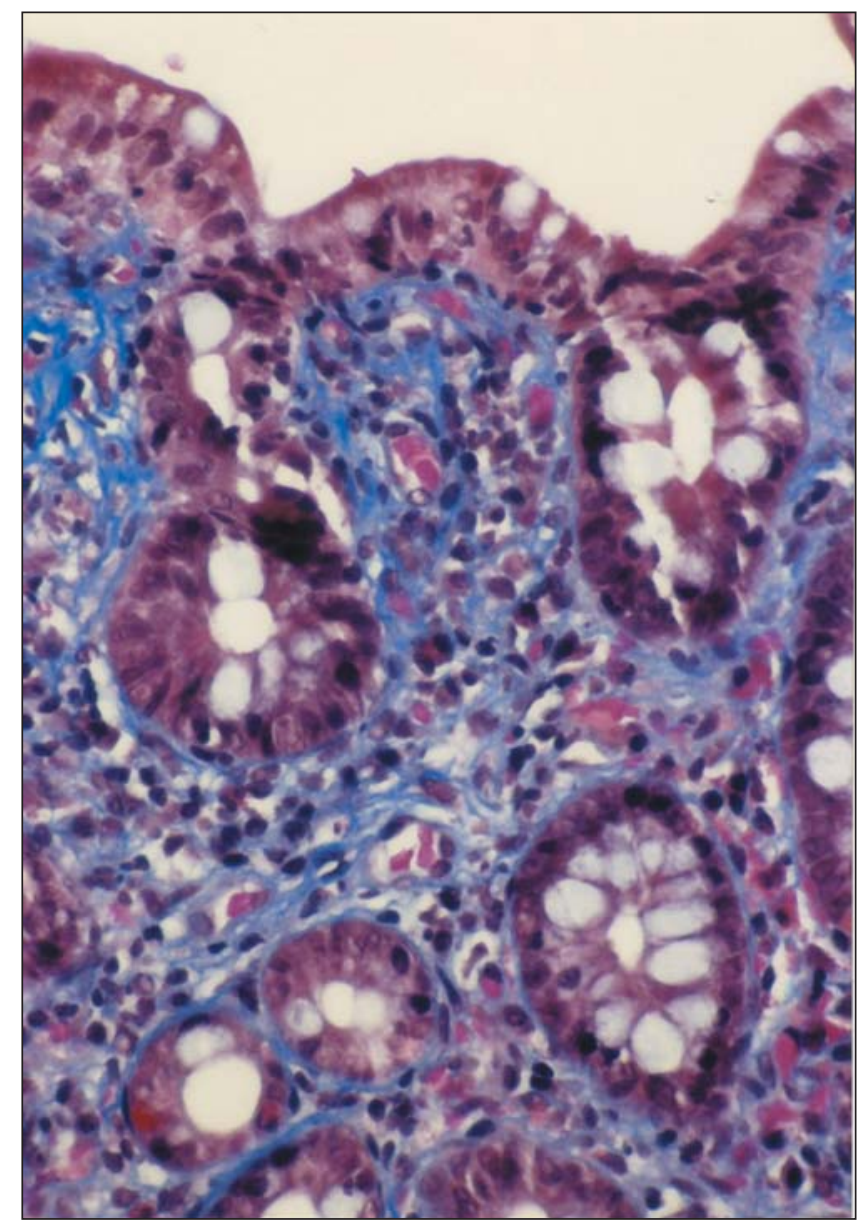

Figure 6) Trichrome-positive small bowel biopsy with prominent blue staining of the subepithelial region (Trichrome stain)

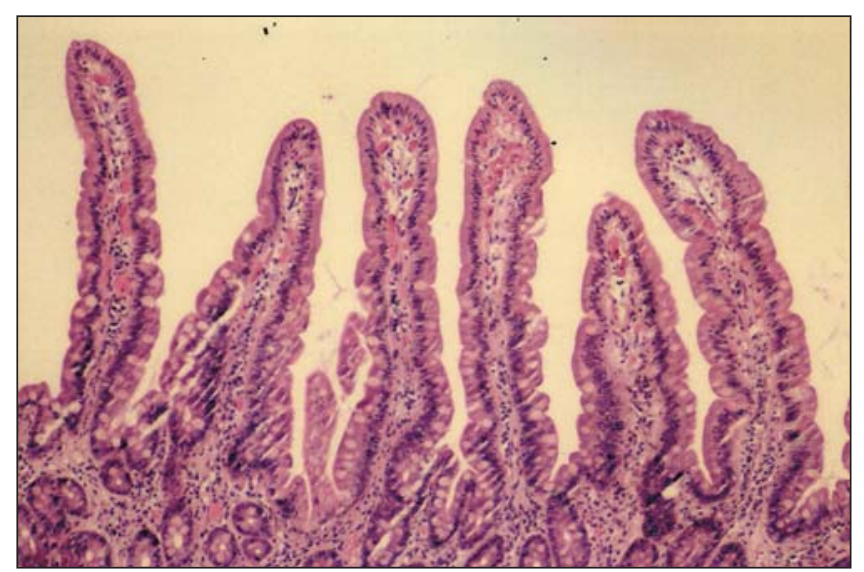

Figure 7) Normal small bowel mucosa after treatment with a glutenfree diet and prednisone (Hematoxylin and eosin stain)

resulted from a gluten-free diet alone (23), and did not necessitate drug therapy. Definition of collagenous colitis in colonic biopsy specimens appears to be a clinical signal that upper gastrointestinal tract disease should be excluded, including occult celiac disease or more extensive collagenous inflammatory mucosal disease. 
In the present patient, treatment was associated with symptomatic improvement. In addition, however, an apparent differential response to treatment, defined by small bowel and colonic biopsy, was evident. In this patient, architectural alterations along with collagen deposited in the small bowel, but not the colon, resolved with treatment, including a gluten-free diet and corticosteroids. This normalization of the small intestine was long-lasting as repeated biopsies from multiple small intestinal sites over more than three years demonstrated no recurrence of collagenous sprue, but persistence of collagenous colitis. The findings both confirm and contrast with another recent report of collagenous involvement in the small and large bowel (21). In that report, complete disappearance of histopathological changes appeared to have occurred in less than one year, however, the differential improvement within the intestinal tract recorded here is a new observation. While

\section{REFERENCES}

1. Weinstein WM, Saunders DR, Tytgat GN, Rubin CE. Collagenous sprue. An unrecognized type of malabsorption. N Engl J Med 1970;283:1297-301.

2. Schein J. Syndrome of nontropical sprue with hitherto undescribed lesions of the intestine. Gastroenterology 1947;8:438-60.

3. Barry RE, Morris JS, Read AE. A case of small intestinal mucosal atrophy. Gut 1970;11:743-7.

4. Neale G. Clinicopathological conference. Case of adult celiac disease resistant to treatment. Br Med J 1968;ii:678-84.

5. Doe WF, Evans D, Hobbs JR, Booth CC. Celiac disease, vasculitis, and cryoglobulinemia. Gut 1972;13:112-23.

6. Holdstock DJ, Oleesky S. Successful treatment of collagenous sprue with combination of prednisolone and gluten-free diet. Postgrad Med J 1973;49:664-7

7. Sheehy TW, Staats OJ. Collagenous sprue. A case report. Ala J Med Sci 1972:9:392-6.

8. Pepper HW, Brandborg LL, Shanser JD, Goldberg HI, Moss AA. Collagenous sprue. Am J Roentgenol Radium Ther Nucl Med $1974 ; 121: 275-82$.

9. Zeman RK, Tomer RG. Collagenous sprue. Am J Gastroenterol 1978;70:541-4

10. Freeman HJ, Weinstein WM, Shnitka TK, Piercey JRA, Wensel RH. Primary abdominal lymphoma. Presenting manifestation of celiac sprue or complicating dermatitis herpetiformis. Am J Med 1977;63:585-94.

11. Freeman HJ. Lymphoproliferative and intestinal malignancies in 214 patients with biopsy-defined celiac disease. J Clin Gastroenterol 2003. (In press)

12. Robert ME, Ament ME, Weinstein WM. The histologic spectrum and clinical outcome of refractory and unclassified sprue. Am J Surg Pathol 2000;24:676-87. this could reflect the natural history of this unusual inflammatory process, rather than treatment per se, these observations indicate for the first time that the etiopathogenetic factors involved in collagenous mucosal inflammatory disease may differentially affect the small and large bowel mucosa. These temporal observations may have important implications for the clinical evaluation of patients with these disorders, as well as their evaluation in response to treatment.

Resolution of pathological changes in small bowel biopsies was not expected. Prior reports have largely regarded collagenous sprue as a disorder defined by severe and relentless panmalabsorption, nutritional disturbance and resistance to dietary or drug treatment. These findings clearly challenge that notion. Future studies will be needed to define the complex pathogenesis of these collagenous inflammatory intestinal disorders.

13. Freeman HJ. Collagenous sprue associated with an extensive T cell lymphoma. J Clin Gastroenterol 2003;36:144-6.

14. Freeman HJ, Weinstein WM, Shnitka TK, Wensel RH, Sartor VE. Watery diarrhea syndrome associated with a lesion of the colonic basement membrane-lamina propria interface. Ann Royal Coll Phys Surg Can 1976;9:45.

15. Lindstrom CG. Collagenous colitis with watery diarrhea - A new entity? Pathol Eur 1976;11:87-9.

16. Eckstein RP, Dowsett JF, Riley JW. Collagenous enterocolitis: A case of collagenous colitis with involvement of the small intestine. Am J Gastroenterol 1988;83:767-71.

17. Borchard F, Niederau C. Collagenous gastroduodenitis. Dtsch Med Wochenschr 1989;114:1345.

18. Stolte M, Ritter M, Borchard F, Koch-Scherrer G. Collagenous gastroduodenitis on collagenous colitis. Endoscopy 1990;22:186-7.

19. McCashland TM, Donovan JP, Strobach RS, Linder J, Quigley EM. Collagenous enterocolitis: A manifestation of gluten-sensitive enteropathy. J Clin Gastroenterol 1992;15:45-51.

20. Castellano VM, Munoz MT, Colina F, Nevado M, Casis B, Solis-Herruzo JA. Collagenous gastrobulbitis and collagenous colitis. Scand J Gastroenterol 1999;6:632-8.

21. Schreiber FS, Eidt S, Hidding M, Schmidt-Walczuch J, Werning C. Collagenous duodenitis and collagenous colitis: A short clinical course as evidenced by sequential endoscopic and histologic findings. Endoscopy 2001;33:555.

22. Freeman HJ. Topographic mapping of collagenous gastritis. Can J Gastroenterol 2001;15:475-8.

23. Freeman HJ. Collagenous colitis as the presenting feature of biopsydefined celiac disease. J Clin Gastroenterol 2003. (In press) 


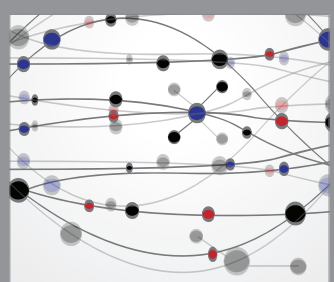

The Scientific World Journal
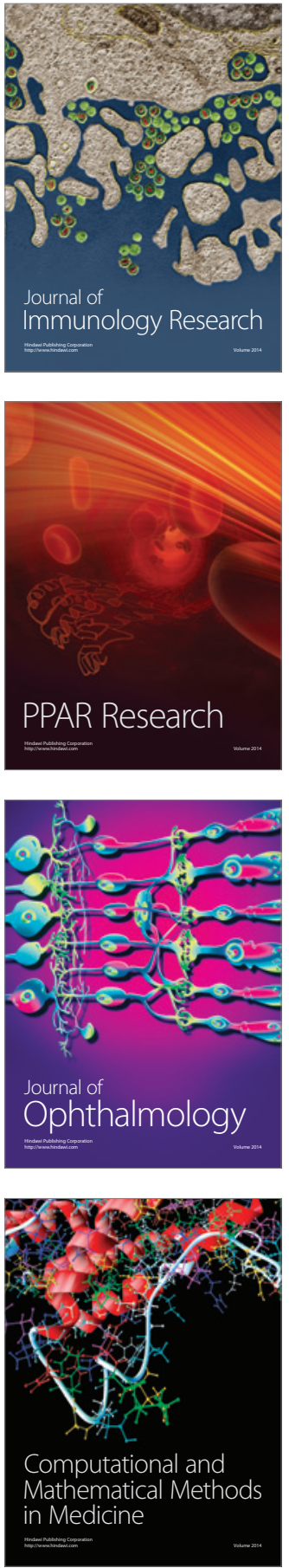

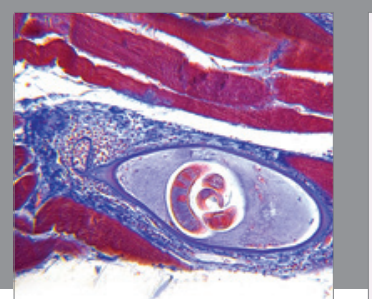

Gastroenterology Research and Practice

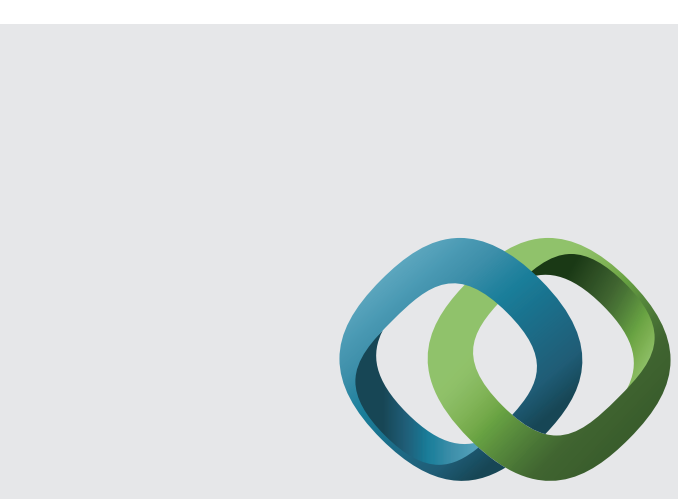

\section{Hindawi}

Submit your manuscripts at

http://www.hindawi.com
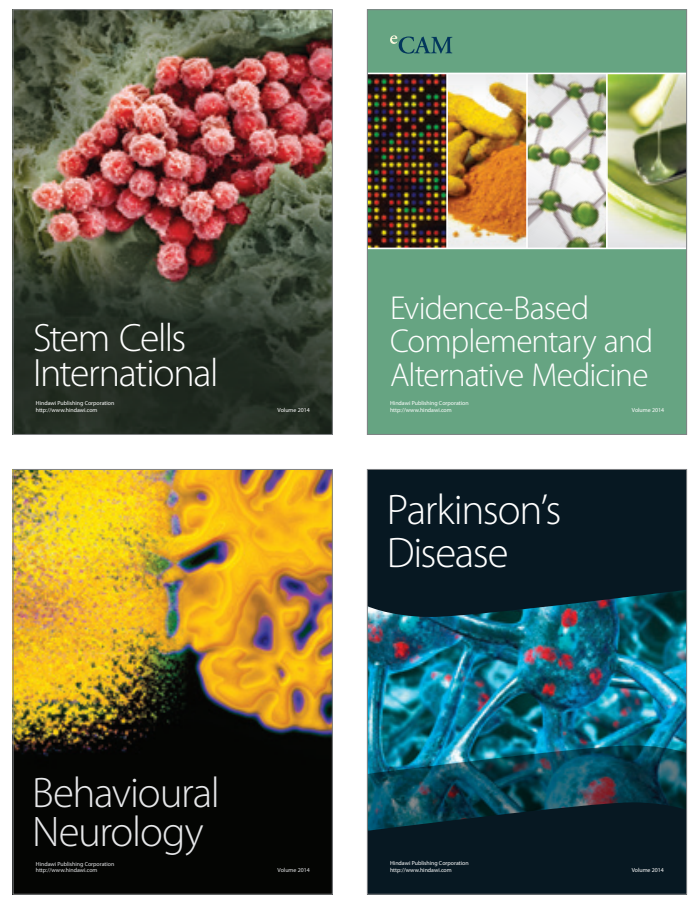
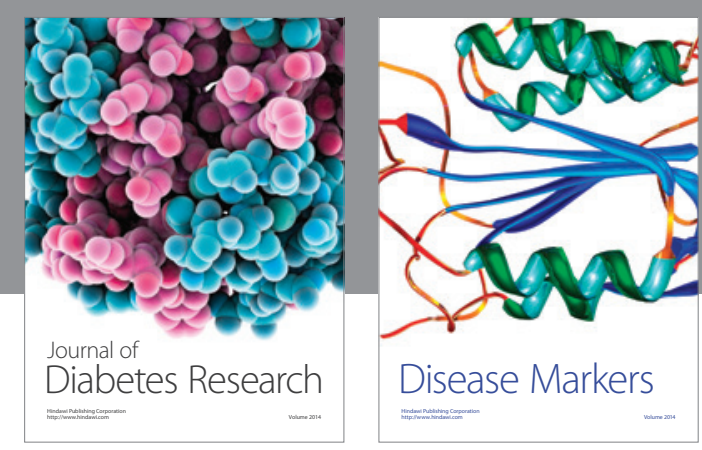

Disease Markers
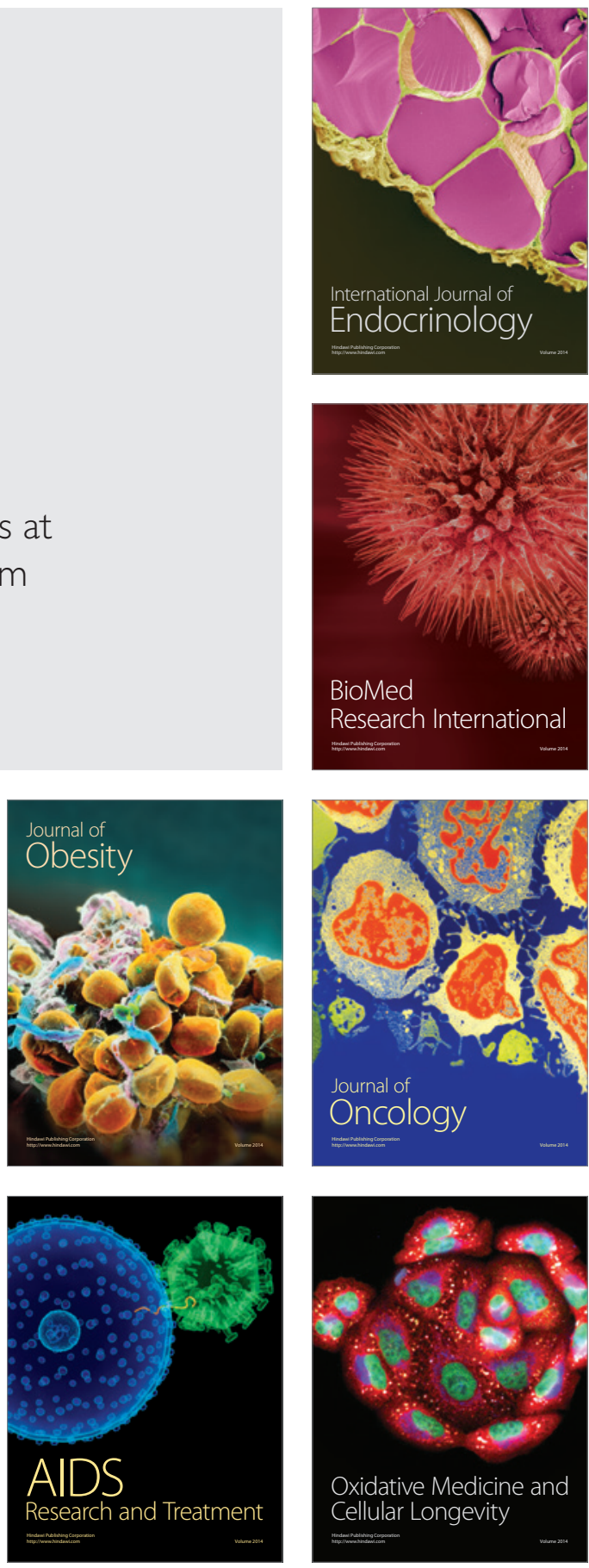